\title{
Dynamic Harmonic Domain Modelling of Space Vector Based UPFC
}

\author{
Devendra Manikrao Holey, Vinod Kumar Chandrakar \\ Department of Electrical Engineering, G. H. Raisoni College of Engineering, Nagpur, India
}

Email address:

dev_mh@yahoo.com (D. M. Holey),vc_vkc@yahoo.co.in (V. K. Chandrakar)

\section{To cite this article:}

Devendra Manikrao Holey, Vinod Kumar Chandrakar. Dynamic Harmonic Domain Modelling of Space Vector Based UPFC. American Journal of Electrical Power and Energy Systems. Vol. 5, No. 1, 2016, pp. 1-10. doi: 10.11648/j.epes.20160501.11

Received: March 12, 2016; Accepted: March 21, 2016; Published: April 6, 2016

\begin{abstract}
This paper presents analytical frequency domain method for harmonic modeling and evaluation of Space Vector Pulse Width Modulation (SVPWM) based unified power flow controller (UPFC). SVPWM is the best among all the PWM techniques. It gives a degree of freedom of space vector placement in a switching cycle. Dynamic modeling technique use for space vector modulation (SVM) based Unified power flow controller (UPFC) for harmonic analysis using dynamic harmonic domain. Performance of the device is evaluated in Dynamic harmonic domain simulation studies using MATLAB environment. The switching function spectra are necessary for harmonic transfer Matrix is calculated using Fourier series.
\end{abstract}

Keywords: Harmonic Domain, Voltage Source Converter (VSC), Space Vector Modulation (SVM), UPFC, STATCOM, SSSC

\section{Introduction}

SVM technique is a digital modulation, to generate PWM load line voltages which is equal to a given load line voltage. By properly selecting the switching states of the inverter and the calculation of the appropriate time period for each state. Low switching frequency PWM techniques, such as phase shifted carrier technique, have been proposed to produce a controllable output voltage satisfying harmonic requirements for utility system [4]. Among other PWM techniques, the Space Vector Modulation (SVM), switching patterns are generated on basis of three-phases, leading to lower switching frequencies than carrier-based techniques shown in [5]. Also, SVM utilizes the DC bus voltage better, and therefore can extend output voltage to closer the square wave operation. These advantages make the SVM a better candidate for especially high power applications. A low switching frequency Delayed Sampling Technique in conjunction with the SVM appropriate for GTO-based high power converter application was proposed in [6]. High quality output voltages is obtained by Low switching frequency SVM strategies [13].

First Harmonic in power system caused by highly non-linear devices degrades its performance. Forced Commutated VSCs are the main building block for low and medium power application. Due to recent development in the semiconductor technology and availability of high power switches e.g. Insulated Gate Bipolar Transistor (IGBT) and Gate Turn Transistor (GTO) have widespread acceptance in for high power VSC's, which are used for FACTS controllers FACTs devices are solution of some power quality problems and also create some power quality problems such as harmonics. The power system harmonic analysis is the calculation of the magnitude, phase of fundamental and higher order harmonic of system signals. The generation of harmonics in present power system is due to large size of power converter. To reduce the harmonics in the system filter and modern switching pattern are used. The increasing prevalence of flexible AC transmission system (FACTS) devices makes having accurate model these devices essential. One attracting method for modeling the steady state performance of these devices is frequency domain analysis [1]. Harmonic phasor contain both positive and negative frequency terms for phase dependence. FACTS devices are characterized by their switching nature.

UPFC is the most important FACTs controller for regulating voltage and power flow in the transmission line. It is made up of two VSCs, one is shunt connected and other is in series. DC capacitor is connected between two VSCs. Series converter provides both active and reactive support whereas shunt 
converter provide necessary power to series converter and also provide reactive power support to the transmission line.

Previous work conducted in Dynamic harmonic domain has been primarily focus on modeling PWM, multi-module based UPFC. The power Quality index can be assess directly from the DHD modeling. Active, reactive, apparent powers as well as power factor are some important power Quality indices. For the linear circuit the indices are defined in term of fundamental frequency whereas for nonlinear circuit, when nonlinear element are present in a circuit such as electronics devices, given on basic of Fourier coefficient or given in terms of Total Harmonic Distortion (THD). For assessment of accurate power Quality indices precise calculation of harmonic component is needed during transient period. Other authors have already made their contribution regarding modeling of FACTS devices and power system element using DHD method [7-8].

There are two methods of DHD modelling first one is that direct mathematical mapping of all system equations and input in frequency domain other method is that does not mapped all equations and input in frequency domain gives more accurate result during transients. In second method method is more suitable for calculation of instantaneous power quality indices, protection analysis and real time application all through it is violating causality and spurious dynamics result provided enough harmonic consider [3]. The time-variant system is converted to time-invariant system and then it is expressed in the dynamic symmetric components. For high power applications, the space vector modulation technique is preferred.

An analytical model of Unified Power Flow Controller (UPFC) for unbalanced operation is given in [12]. It is assumed that the PWM control eliminates low harmonic distortion. But in real systems this is not always true. The harmonic domain model of a VSC is proposed for HVDC-VSC back-to-back and HVDC-VSC transmission shows that VSC HVDC system generate harmonic and interact with on the power system [14]. The transient model and control system of UPFC is presented for the fast dynamic response in [16]

Mathematical model of unified power flow controller (UPFC) for steady state, transient stability a eigen value studies is given [17] The application of a space vector modulation (SVM) strategy for a multimodule back-to-back HVDC converters for low switching frequency that minimizes ac-side low-order voltage harmonics. SVM strategy based on sequential sampling technique by appropriately introducing transient due to circuit parameters changes are used. Second

phase shift for the corresponding voltage harmonics of the converter modules and maintaining the fundamental voltage components of VSC in-phase to obtain maximum ac-side voltage is presented in [18]. It eliminates the requirement of transformer arrangement for harmonic reduction, only simple arrangement of transformer can be used [18].

Dynamic harmonic domain model for UPFC is already developed by other authors for PWM converters. Now a day advance switching techniques such SVPWM are used for the high power application due to low switching frequency and easy to implement digitally. Dynamic harmonic domain model for SVPWM based UPFC does not found in literature. To extend the results obtained by other authors in the modeling of UPFC FACTS device, the proposed SVPWM VSC based UPFC model is developed in order to obtained the evolution in the of harmonic interference of the UPFC. Dynamic Harmonic analysis of PWM based UPFC is shown in [7]. This paper present the Dynamic analysis of SVPWM based UPFC during steady state and dynamic condition is given. This gives the information about harmonic indices during transient condition also. This can be used for control system design for Space vector based UPFC as space vector modulation scheme which is suitable for digital implementation. The paper is organized as follows. The second section provides fundamentals of DHD method. Third section is fundamental of Space Vector based pulse width modulation based voltage source converter; Fourth section is deal with DHD modeling of SVPWM VSC used for UPFC; this arrangement is used in this paper

\section{Dynamic Harmonic Domain Basic}

The system given by Ordinary Differential Equations (ODE) can be transform to an alternative arrangement called the Dynamic Harmonic Domain, based on the approximation of the system by Fourier series over a period of the fundamental frequency. Linear periodic system (LTP) is converted into linear time domain (LTI) system using dynamic harmonic domain (DHD).

Consider a LTP system is given by

$$
\begin{array}{lll}
x t & A t x t & B t u t \\
y(t) & C t x t & D t u t
\end{array}
$$

Where $\mathrm{A}(\mathrm{t})$ is given as

$$
\mathrm{A} \mathrm{t} \quad a_{h} e^{j h{ }_{0} t} \quad \cdots \quad a_{1} e^{j_{0} t} \quad a_{0} \quad a_{1} e^{j_{0} t} \quad \cdots \quad a_{h} e^{j h{ }_{0} t}
$$

Where $\mathrm{h}$ is the highest harmonics of interest and $\omega 0$ is the fundamental frequency of the system. Equation (1) can be represented in the Fourier series, the ordinary differential equation to an alternative DHD representation.

Therefore

$$
\begin{array}{cccc}
\dot{X} & A & S & B U \\
Y & C X & D U &
\end{array}
$$

Variable given in the equation (1) can transform into the vectors in the equation (3) with their coefficient related to the 
harmonic components of their instantaneous signals as,

$$
X=\left[X_{-h}(t) \cdots X_{-1}(t) X_{0}(t) X_{1(t)} \cdots X_{h}(t)\right]
$$

$\mathrm{S}$ is the matrix of differential and given by

$$
S=\operatorname{diag}\left[-j h \omega_{0} t \cdots-j \omega_{0} \quad 0 j \omega_{0} t \cdots j h \omega_{0}\right]
$$

The matrices A, B, C and D has Toeplitz structure and their time domain counterpart such that

$$
A=\left[\begin{array}{ccccccc}
A_{0} & A_{-1} & \cdots & A_{-h} & & & \\
A_{1} & \ddots & \ddots & \ddots & \ddots & & \\
\vdots & \ddots & A_{0} & A_{-1} & \ddots & \ddots & \\
A_{h} & \ddots & A_{1} & A_{0} & A_{-1} & \ddots & A_{-h} \\
& \ddots & \ddots & A_{1} & A_{0} & \ddots & \vdots \\
& & \ddots & \ddots & \ddots & \ddots & A_{-1} \\
& & & A_{h} & \cdots & A_{1} & A_{0}
\end{array}\right]
$$

The steady state solution is obtained directly from equation (3), considering ( $\left.\begin{array}{ll}\dot{X} & 0\end{array}\right)$ gives,

$$
\begin{array}{lll}
X & (S & A){ }^{1} B U \\
Y & C X & D U
\end{array}
$$

The matrices $\mathrm{A}, \mathrm{B}, \mathrm{C}$ and $\mathrm{D}$ are constant and input $\mathrm{U}$ is also constant. The solution of $\mathrm{X}$ and $\mathrm{Y}$ is obtained from equation (4). The solution of equation (4) can be used to initialize the DHD simulation in time domain.

\section{Space Vector Modulation}

\subsection{Principles of SVPWM}

Signal processing view point space vector modulation is a digital modulation technique. SVPWM is based in such a way that there are only two independent variables in a three-phase system. Orthogonal coordinates are used to represent the 3 -phase voltage in the phasor diagram. A three-phase voltage vector represented by complex space vector as in equation 1 neglecting zero sequence components [10-11]

$$
\begin{array}{llllll}
V & 2 & \frac{1}{2} & \frac{1}{2} & \text { Van } \\
V & \underline{2}^{1} & { }^{2} & 3 / 2 & 3 / 2 & V b n
\end{array}
$$

SVM use the combinations of switching states to approximate the locus of Vref. In $\alpha-\beta$ plane a hexagon centered at origin of $\alpha \beta$ plane, identifies the space vectors shown in fig. 1. Which is divide into six sectors. Each sector covers the space corresponding to 600 .

The distinct possible switching states of the 2-level VSC are represented as eight voltage vectors, out of which six are active states (V1-V6) and two are null states (V0, V7). The active states contribute output line voltage as $+\mathrm{Vdc}$ or $-\mathrm{Vdc}$, where as null states do not contribute any output voltage for VSC. The eight voltage vectors are shown in Table 1. In table 1 denotes ON state of the switch and 0 denotes OFF state of the switch.

The reference vector is synthesized by the three adjacent switching vectors. For example, when Vref falls into sector I as shown in Fig. 2, it can be synthesized by V1, V2 and V0. The optimum PWM modulation is expected if the sampling rate is as high as possible, only two non-zero switching states adjacent to the reference and one zero switching state are used to synthesize the reference vector, and the cycle wherein the average voltage vector becomes equal to the reference vector consists of three successive switching states only. This gives

$$
V_{r e f} T_{s} \quad V_{1} T_{1} \quad V_{2} T_{2} \quad V_{0} T_{0}
$$

Where Ts is the period of the switching cycle, T1 and T2 are the switching times of the vectors V1 and V2.

$\mathrm{T} 1$ and $\mathrm{T} 2$ are calculated as

$$
\begin{aligned}
& T 1 \quad \frac{\text { Vref }}{\frac{2}{3}} T s \frac{\sin (60)}{\sin 60} \\
& \text { T2 } \frac{\text { Vref }}{\frac{2}{3}} T s \frac{\sin }{\sin 60} \\
& \begin{array}{llll}
T_{0} & T_{s} & T_{1} & T_{2}
\end{array}
\end{aligned}
$$

Similar calculation is applied to sector II to VI Vector V8 can be used in place of V7. The choice is based on the requirement to minimize average number of switching per cycle.

The Maximum value of $\mathrm{V}_{\text {ref }}$ is obtain when $\theta=30^{\circ}$ and $\mathrm{V}_{\text {ref }}$ is given by

$$
\max V_{r e f}=\cos 30^{\circ} \sqrt{\frac{2}{3}} V_{d c}
$$

This is the maximum value of line to line voltage injected by the converter. The maximum magnitude of Vref is also the radius of circle inscribed in the hexagon shown in fig. 1 The Square wave converter generates a space vector of magnitude $\sqrt{6} / \pi \mathrm{Vdc}$ the maximum value of the modulation index as

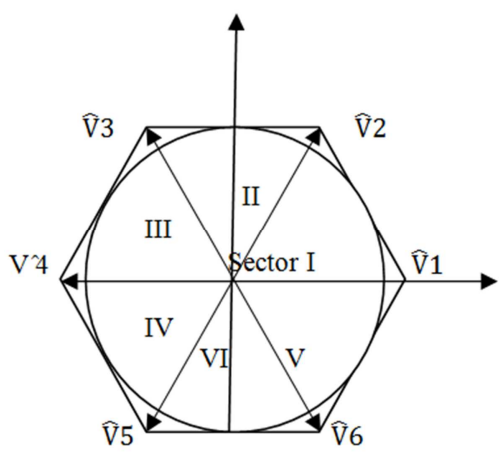

Fig. 1. Switching Vector of 2-level converter in $\alpha \beta$ plane. 


$$
m_{\max }=\frac{\pi}{\sqrt{6} \sqrt{2}}=0.907
$$

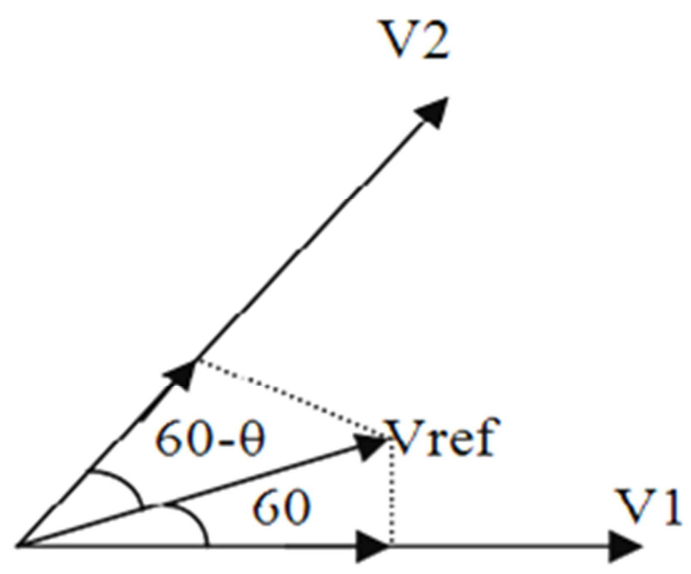

Fig. 2. Representation of reference vector.

Table 1. 2-Level Inverter Voltage Vectors Voltage Vectors.

\begin{tabular}{lllllll}
\hline \multirow{2}{*}{ S. No. } & $\mathbf{S}_{\mathbf{a}}$ & $\mathbf{S}_{\mathbf{b}}$ & $\mathbf{S}_{\mathbf{c}}$ & & \multicolumn{3}{c}{ Line to Neutral voltage } \\
\cline { 5 - 7 } & & & & Van & Vbn & Vcn \\
\hline 1 & 1 & 0 & 0 & $\mathrm{Vdc}$ & 0 & 0 \\
2 & 1 & 1 & 0 & $\mathrm{Vdc}$ & $\mathrm{Vdc}$ & 0 \\
3 & 0 & 1 & 0 & 0 & $\mathrm{Vdc}$ & 0 \\
4 & 0 & 1 & 1 & 0 & $\mathrm{Vdc}$ & $\mathrm{Vdc}$ \\
5 & 0 & 0 & 1 & 0 & 0 & $\mathrm{Vdc}$ \\
6 & 1 & 0 & 1 & $\mathrm{Vdc}$ & 0 & $\mathrm{Vdc}$ \\
7 & 1 & 1 & 1 & $\mathrm{Vdc}$ & $\mathrm{Vdc}$ & $\mathrm{Vdc}$ \\
8 & 0 & 0 & 0 & 0 & 0 & 0 \\
\hline
\end{tabular}

\subsection{Switching Vector Model of VSC}

The General switching function is obtained in time domain for space vector modulation. The harmonic content in switching function is given by Fourier series.

$$
\begin{aligned}
& \text { Sa } t{ }_{n}^{h} S a e^{j n 0 t} \\
& S_{b(t){ }_{n}{ }_{h}^{h}} S_{b} e^{j n{ }_{0} t} \\
& S_{c(t){ }_{n}{ }_{h}} S_{c} e^{j n_{0} t}
\end{aligned}
$$

Where $\mathrm{Sa}, \mathrm{Sb}, \mathrm{Sc}$ are switching function obtained by using SVPWM algorithm. The line switching vector is defined as

$$
\begin{array}{lll}
S_{a b} & S_{a} & S_{b} \\
S_{b c} & S_{b} & S_{c} \\
S_{c a} & S_{c} & S_{a}
\end{array}
$$

The switching vector for harmonic domain is defined as

$$
\begin{aligned}
& S_{a b} \\
& S_{1} \quad S_{b c} \quad, S_{2} \quad S_{a b} \quad S_{b c} \quad S_{c a} \\
& S_{c a}
\end{aligned}
$$

\section{Dynamic Harmonic Domain Modelling of SVPWM Based UPFC}

The Unified Power Flow Controller (UPFC) is the important tool for real-time control of $\mathrm{AC}$ transmission system. It used to control the transmitted real and reactive-power flows through a transmission line, improving the transient stability margins, damping power oscillations and providing voltage support. DHD model of UPFC is presented in [7] considering selective harmonic elimination method. In preceding discussion we extent model proposed in [7] considering space vector modulation techniques. Figure 3 shows the equivalent circuit of UPFC connected the transmission lines. It consists of two VSCs connected to common DC capacitor. One VSC connected in shunt act as a STATCOM and other connected in series act as SSSC. $\mathrm{Re}+\mathrm{jXe}$ shows the resistance and impedance of coupling transformer. The three-phase voltages and currents on the AC side of the SSSC are $\mathrm{V}_{\mathrm{ABCl}}(\mathrm{t})$ and, $\mathrm{i}_{\mathrm{ABC}}(\mathrm{t})$, The three-phase voltages and currents on the AC side of the STATCOM are $\mathrm{V}_{\mathrm{abcl}}(\mathrm{t})$ and, $\mathrm{i}_{\mathrm{abc}}(\mathrm{t})$ respectively and the DC side voltage $\mathrm{vdc}(\mathrm{t})$, DC side current $i_{1}(t), i_{2}(t)$. The voltage and current on $A C$ side in terms of switching function is given as

$$
\begin{array}{cc}
V_{a b c 1} t & p_{S 1} t . v_{d c}(t) \\
V_{A B C 1} t & p_{S 2} t . v_{d c}(t) \\
i_{1} t & q_{S 1} t \cdot i_{a b c}(t) \\
i_{2} t & q_{S 2} t . i_{A B C}(t)
\end{array}
$$

$\mathrm{V}_{\mathrm{ABCl}}(\mathrm{t})$ and $\mathrm{i}_{\mathrm{ABC}}(\mathrm{t})$ are three phase voltage and current vectors given by:

$$
\begin{array}{lllll}
V_{A B C 1} t & v_{A 1}(t) & v_{B 1}(t) & v_{C 1}(t) \\
i_{A B C} t & i_{A}(t) & i_{B}(t) & i_{C}(t)^{T}
\end{array}
$$

Where ps1(t), ps2(t) and qs1(t), qs2(t) are transformation vectors [12], [13], which are given by:

$$
\begin{gathered}
P_{s 1}=\left[\begin{array}{l}
S_{a b 1}(t) \\
S_{b c 1}(t) \\
S_{c a 1}(t)
\end{array}\right] \\
P_{s 2}=\left[\begin{array}{l}
S_{a b 2}(t) \\
S_{b c 2}(t) \\
S_{c a 2}(t)
\end{array}\right]
\end{gathered}
$$




$$
\begin{aligned}
& q_{s 1}(t)=\left[\begin{array}{lll}
S_{a b 1}(t) & S_{b c 1}(t) & S_{c a 1(t)}
\end{array}\right] \\
& q_{s 2}(t)=\left[\begin{array}{lll}
S_{a b 2}(t) & S_{b c 2}(t) & S_{c a 2}(t)
\end{array}\right]
\end{aligned}
$$

The time domain state equation of UPFC is:

$$
\frac{d V_{d c} t}{d t} \quad \frac{1}{C}\left(i_{1} t \quad i_{2} t\right)
$$

Substitute the values of i1(t), i2( $(\mathrm{t})$ gives:

$$
\begin{aligned}
& \frac{d V_{d c} t}{d t} \quad \frac{1}{C}\left(q_{s 1} t i_{a b c} t \quad q_{s 2} t i_{A B C} t\right) \\
& \frac{d i_{a b c} t}{d t} \quad \frac{R_{e}}{L_{e}} i_{a b c} t \quad V_{a b c} t \quad V_{a b c 1} t
\end{aligned}
$$

$$
\frac{d i_{A B C} t}{d t} \quad \frac{R_{e}}{L_{e}} i_{A B C} t \quad V_{A B C} t \quad V_{A B C 1} t
$$

Current in AC side of STATCOM and SSSC in terms of switching function is

$$
\frac{d i_{a b c} t}{d t} \quad \frac{R_{e}}{L_{e}} i_{a b c} t \quad \frac{1}{L_{e}}\left(V_{a b c} t \quad p_{s 1} t V_{d c} t\right)
$$

$$
\frac{d i_{A B C} t}{d t} \quad \frac{R_{e}}{L_{e}} i_{A B C} t \quad \frac{1}{L_{e}}\left(V_{A B C} t \quad p_{s 2} t V_{d c} t\right)
$$

IS

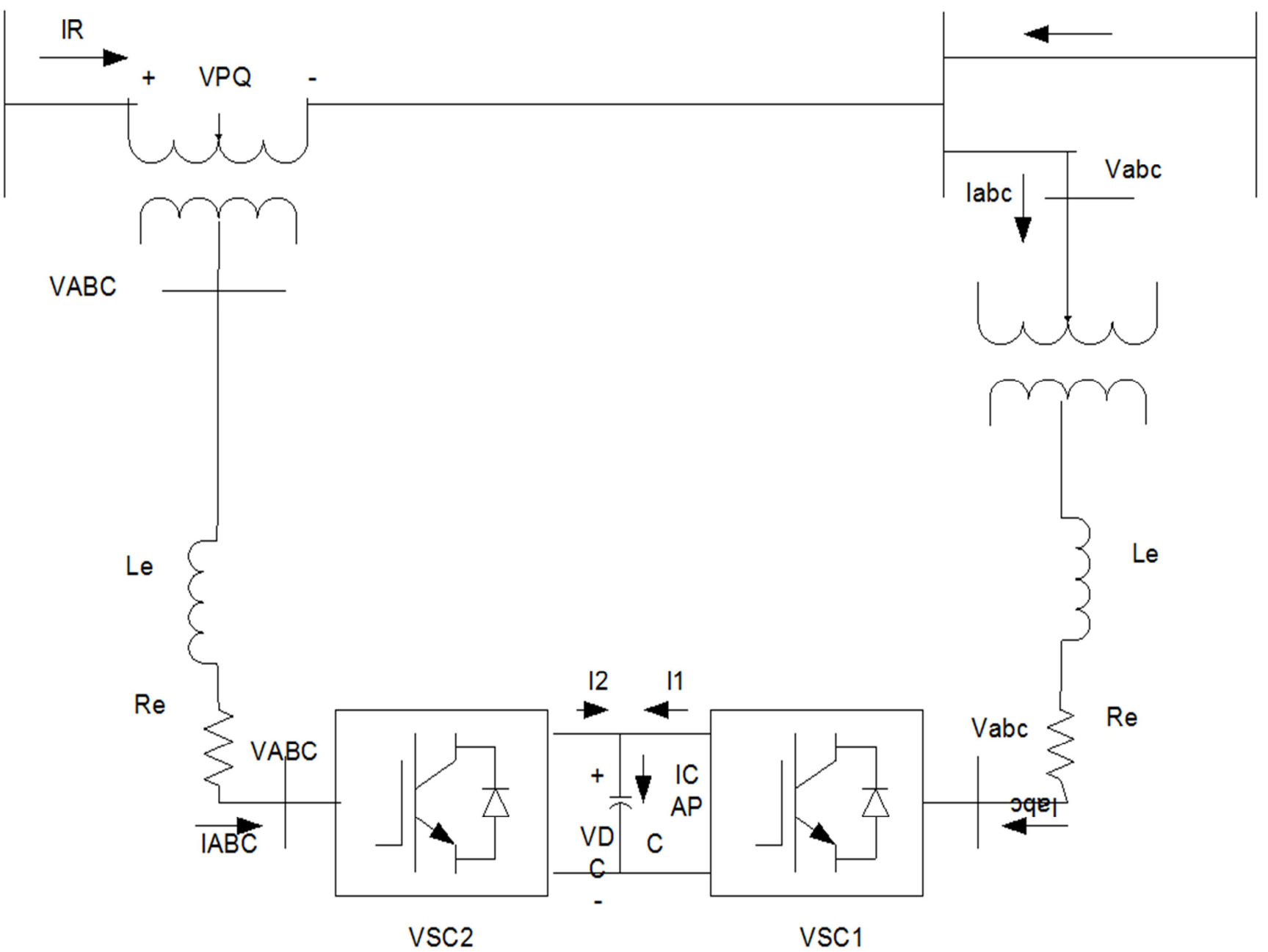

Fig. 3. Unified Power flow controller (UPFC).

The linear time periodic equations $(24,27 \& 28)$ in matrix form will be written as: 


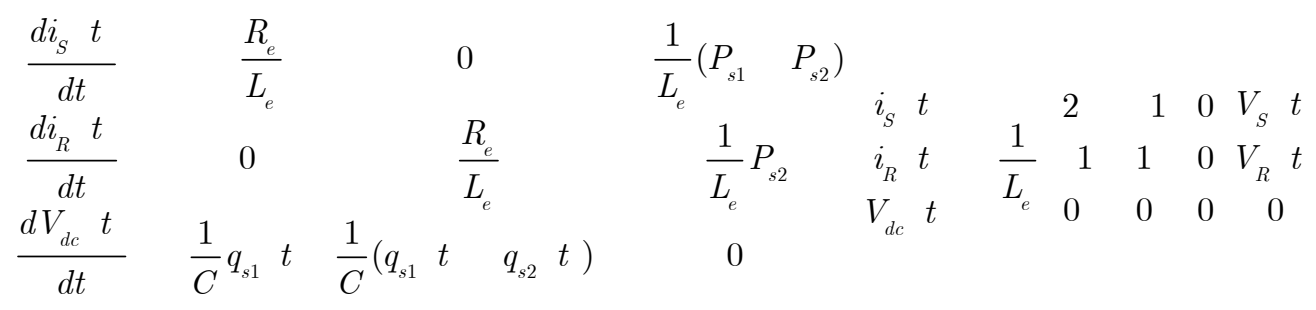

The equation (29) can be transfer to linear time invariant equation considering theory of DHD analysis as:

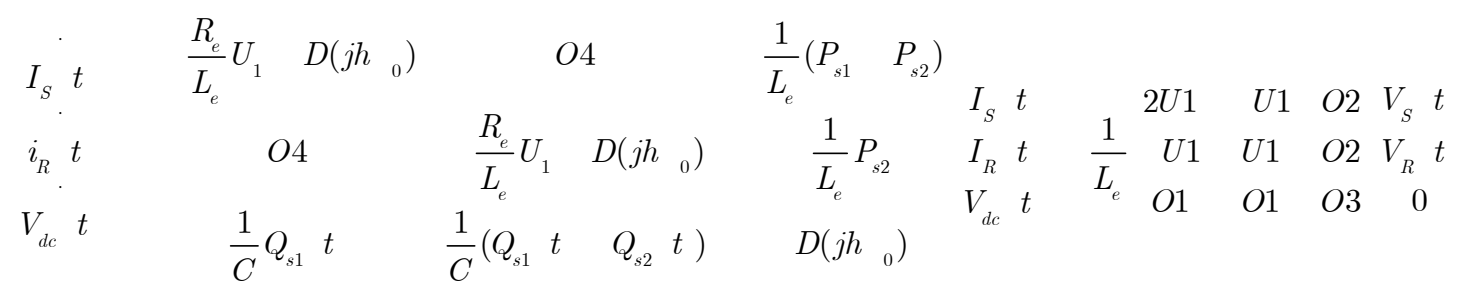

The initial condition is obtained by considering derivatives of state variables as zero gives:

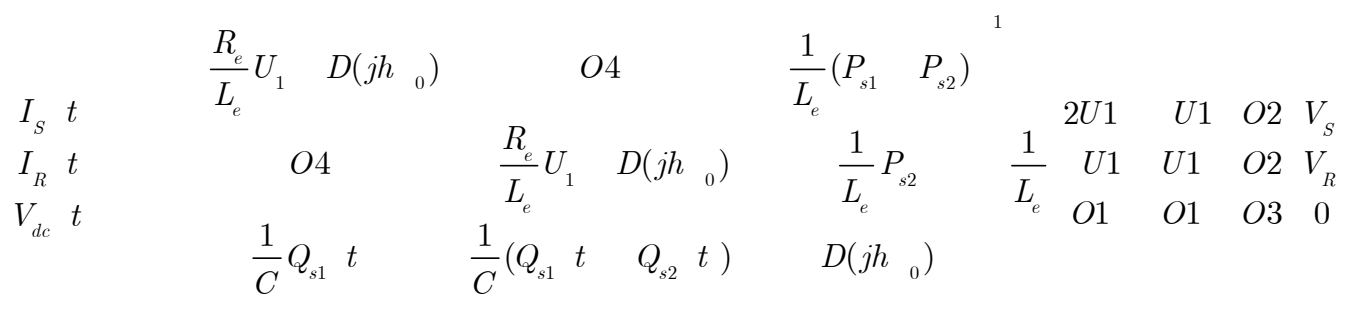

\section{Simulation}

In order to access dynamic harmonics response including power quality indices, The per-phase inductive reactance and resistance of the coupling transformer and the capacitance of the dc capacitor are $\mathrm{R},=0.04 \Omega, \mathrm{L}=0.2 \mathrm{mH}$ and $\mathrm{C}=5000 \mu \mathrm{F}$, respectively.

Under steady state conditions the bus per phase voltages $V_{R}$ and $\mathrm{V}_{\mathrm{S}}$ in volts at $50 \mathrm{~Hz}$ are

$$
\begin{aligned}
& V_{R a}(t)=\sin \omega_{0} t, V_{S a}(t)=\sin \omega_{0} t \\
& V_{R b}(t)=\sin \left(\omega_{0} t-120^{\circ}\right), V_{S b}(t)=\sin \left(\omega_{0} t-120^{\circ}\right) \\
& V_{R c}(t)=\sin \left(\omega_{0} t+120^{\circ}\right), V_{S c}(t)=\sin \left(\omega_{0} t+120^{\circ}\right)
\end{aligned}
$$

Assume disturbances in the voltages starting at 0.04 seconds and lasting for 0.005 seconds. During disturbances voltages on the VS bus is $150 \%$ of the original value. The simulation was started at to $=0$ seconds with final time $\mathrm{tf}=$ 0.1 seconds and an integration time step is $0.001 \mathrm{~s}$. 50 harmonics are considered. System is simulated using MATLAB software.

Fig. 4.a. Shows current at terminal of VSC1 which is shunt connected. Its RMS value is shown in fig. 4.c. Shows that during disturbances fundamental component of STATCOM current increases. Fig. 4.b. shows harmonic component of SSSC current. Fig. 4.d. shows the RMS value of SSSC current. It is observed that during disturbances RMS value of fundamental current increases. Fig. 4.e. shows the harmonic component of voltage at the terminal of VSC1. It shows those harmonic components are well within the range. Fig. 4.f. shows the harmonic component of the voltage on the capacitor. Fundamental component of capacitor voltage is constant by using SVPWM techniques without using any control to maintain capacitor voltages constant. It shows that during disturbances exhibits the dynamic behavior of only the $1^{\text {st }}, 3^{\text {rd }}$, $5^{\text {th }}$ and $7^{\text {th }}$ harmonic components with time for the phase-a is shown in fig. 4.

UPFC's dynamic power quantities of all the three phases are shown in Fig. 5. fig. 5.a. shows the active power absorb by STATCOM. It shows that STATCOM absorb the more active power during disturbances. Fig. 5.b. shows the apparent power on for the VSC1 and for VSC2. It shows that during disturbances SSSC supplied the apparent power to the system. Fig. 5.c. shows the active power supplied by SSSC. During steady state SSSC is not supplying power to the system but STATCOM is absorbing the active power to compensate the looses occurs in the SSSC and STATCOM circuits. Fig. 5.d. and Fig. 5.f. shows the reactive power supplied by SSSC and STATCOM whereas Fig. 5.c. shows the distorted power at STATCOM terminals.

The voltage and the current THD of the SSSC and STATCOM in all three phases are shown in Fig. 6. THD are within the range as per standards. 


\section{Conclusion}

This paper presents the Space Vector based switching strategy for a UPFC that utilize the voltage source converter to minimize the harmonic at the point of common contact. The linear time periodic equation is converted into linear time invariant system which is done using dynamic harmonic domain for calculation of harmonic interference in the system

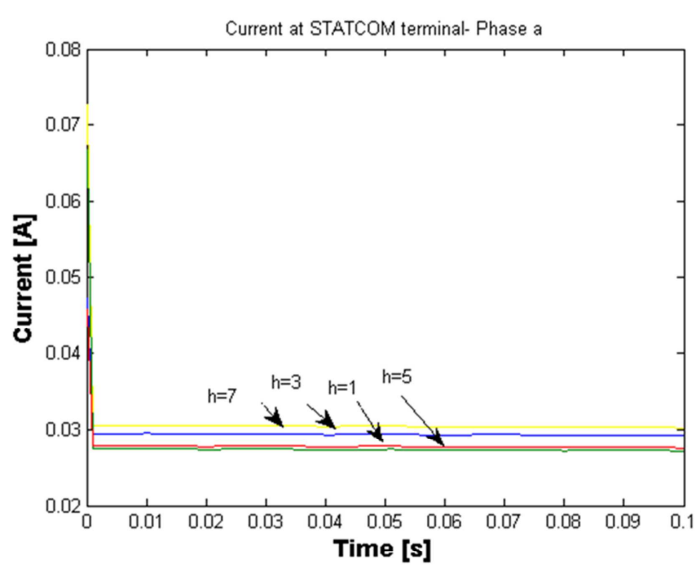

4.a. Current at STATCOM terminal Phase A

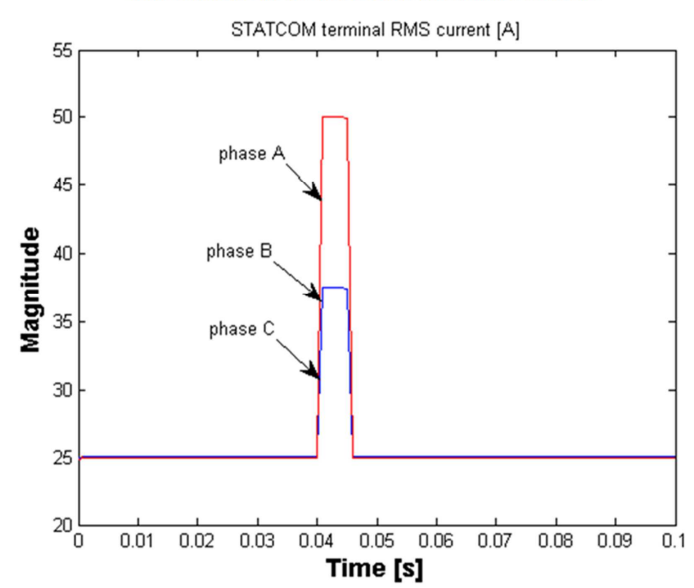

4.c. RMS Value of STATCOM Current

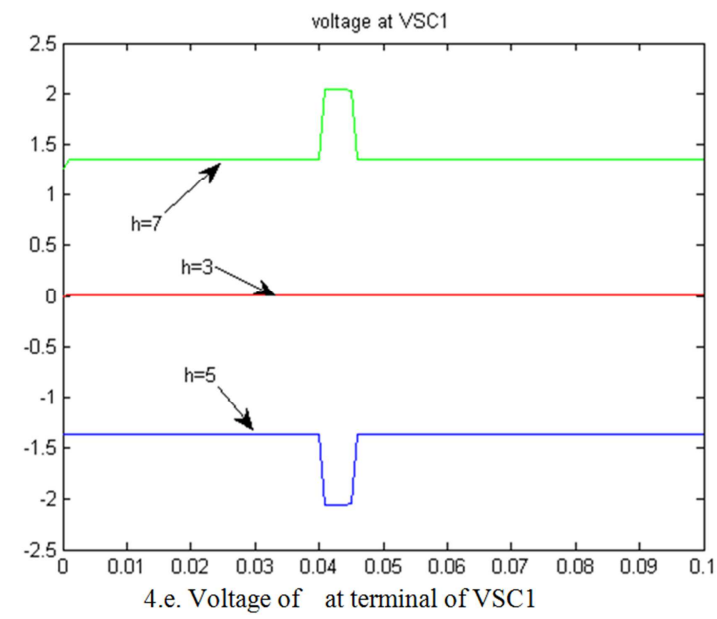

during transient and evaluated based on dynamic harmonic domain algorithms using MATLAB code.

The proposed model is used to calculate harmonic interference produced by space vector based UPFC. It gives accurate result and information about harmonics indices during transient operation of system as compared to time domain simulation. Harmonics indices are important for designing control system for the system.

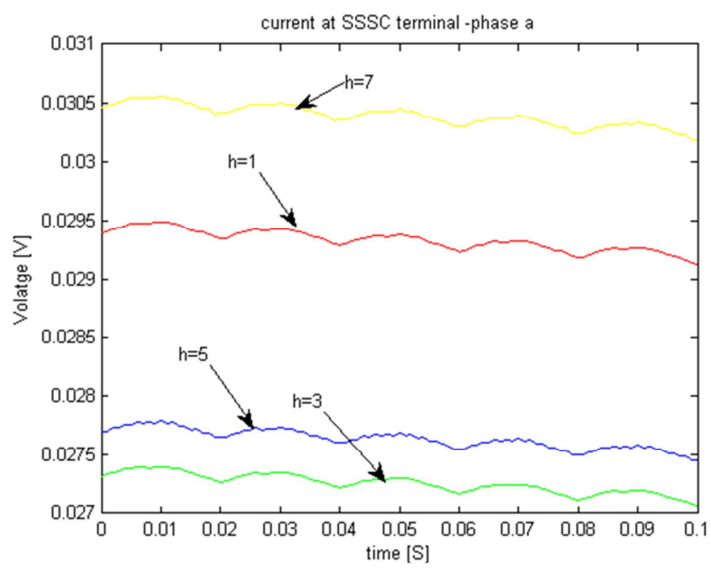

4.b. Current at SSSC terminal Phase A

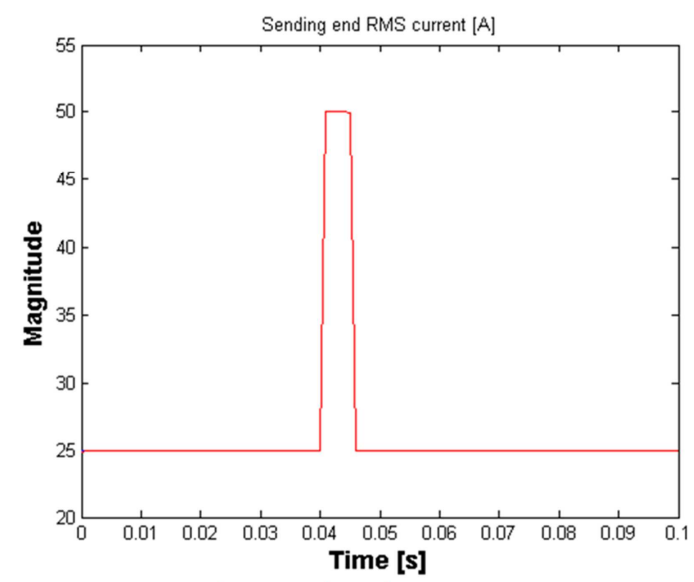

4.d. RMS value of SSSC Current

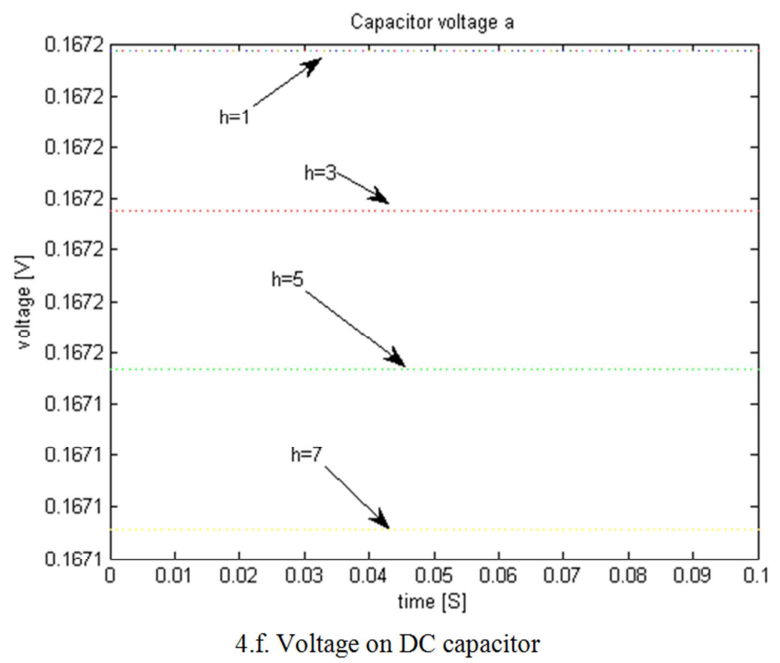

Fig. 4. Voltage and current at Converter terminal. 


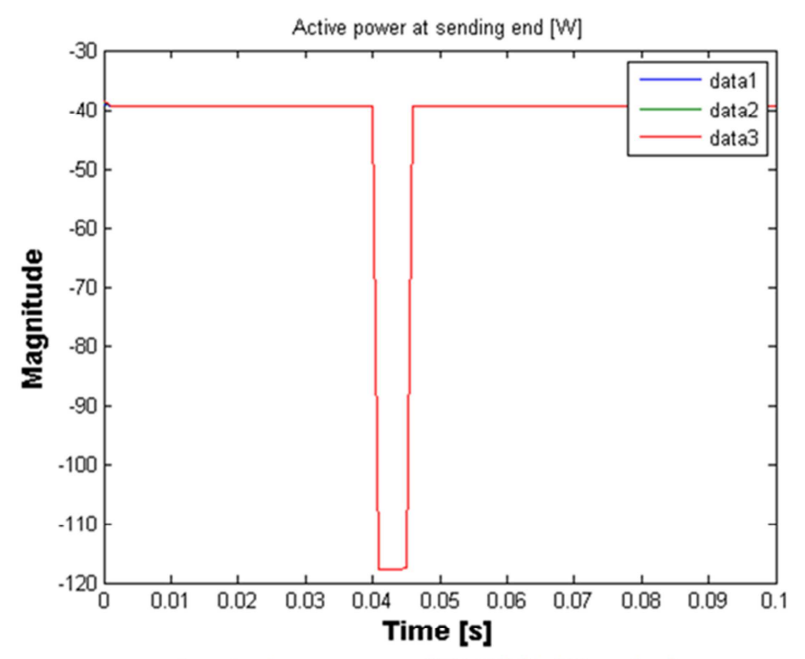

5.a. Active power at STATCOM Terminal

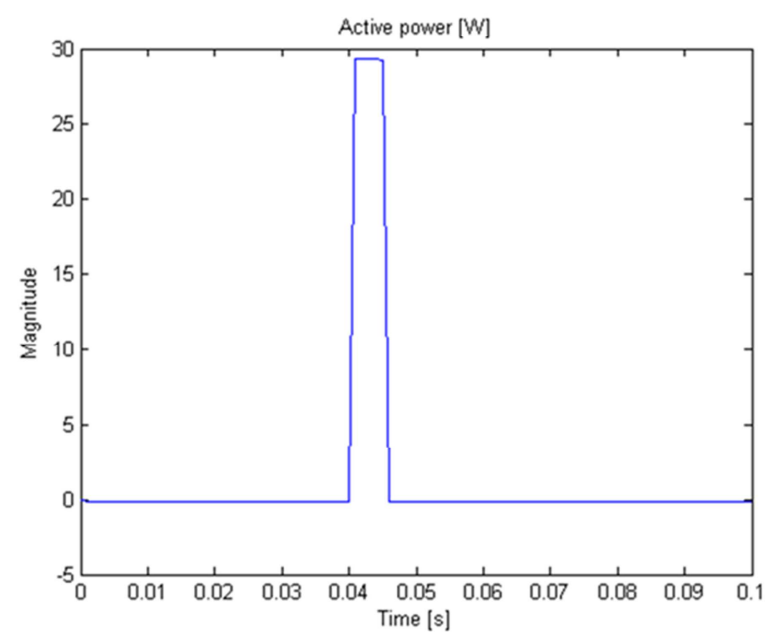

5.c Active power at SSSC Terminal

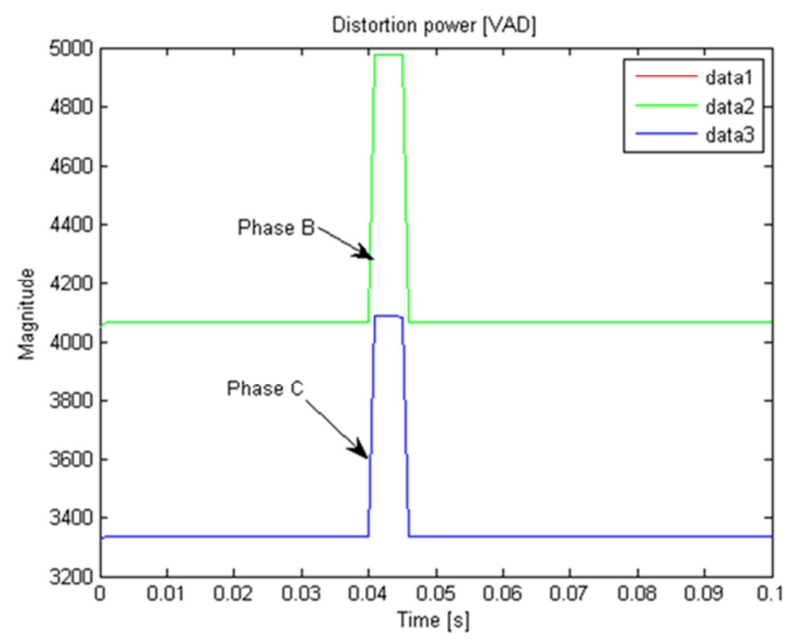

5.e. Distorted Power at STATCOM Terminal

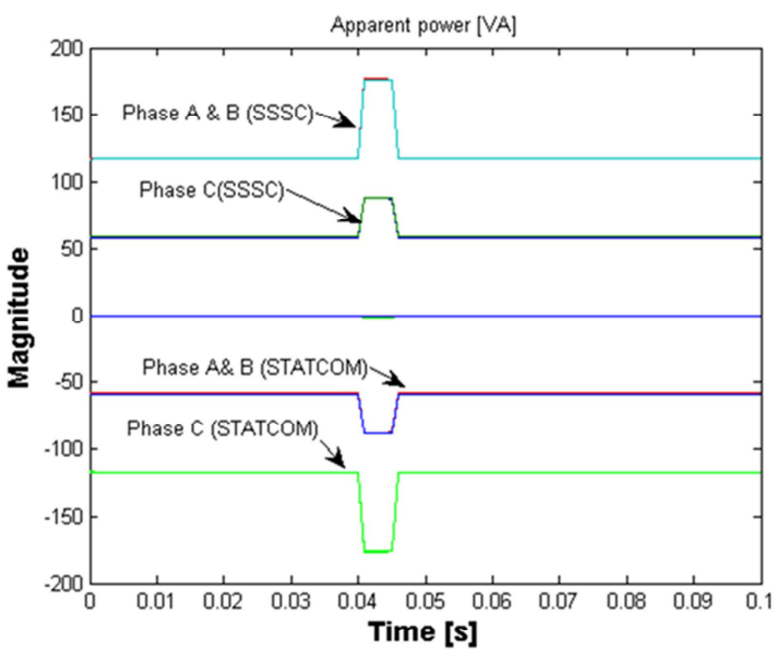

5.b. Apparent power at STATCOM and SSSC terminals

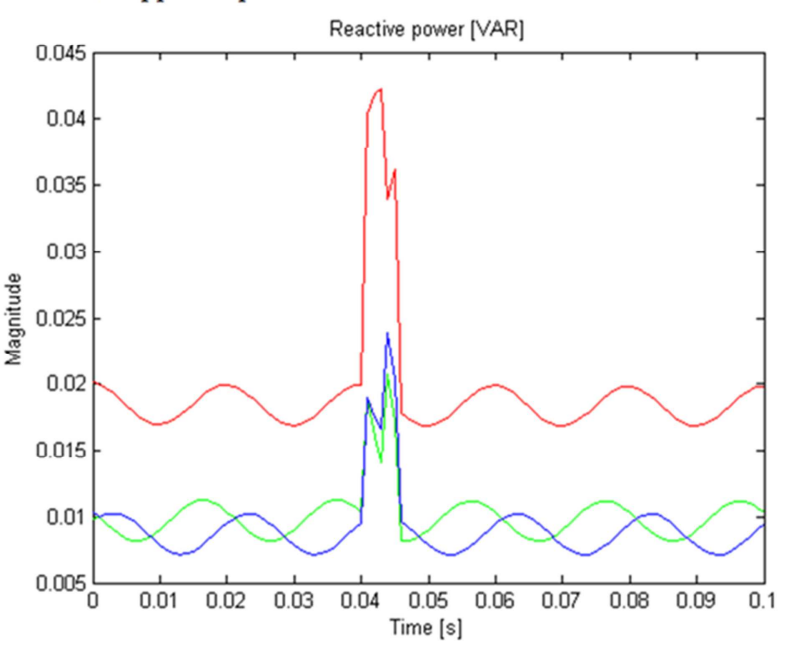

5.d. Reactive power at SSSC Terminal

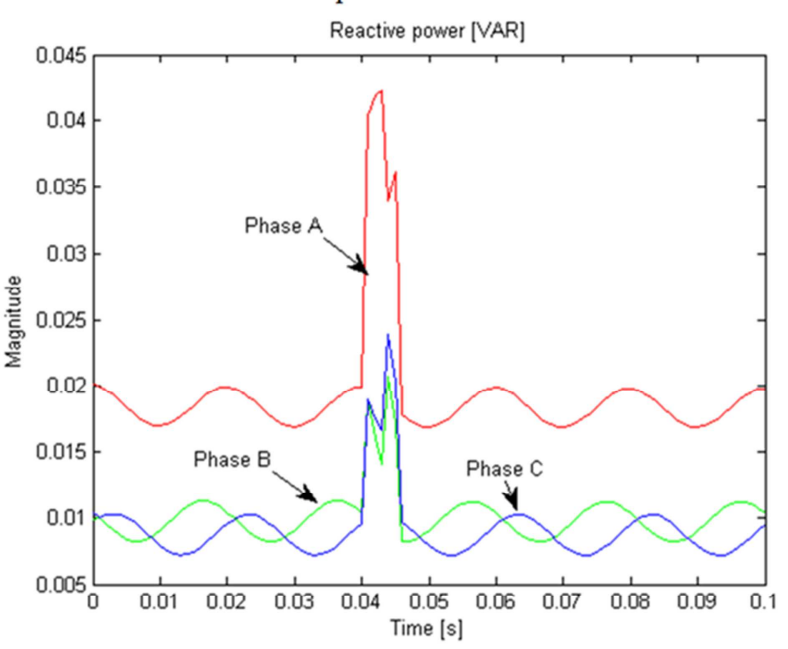

5.f. Reactive power at STATCOM Terminal

Fig. 5. UPFC terminal electric quantities. 


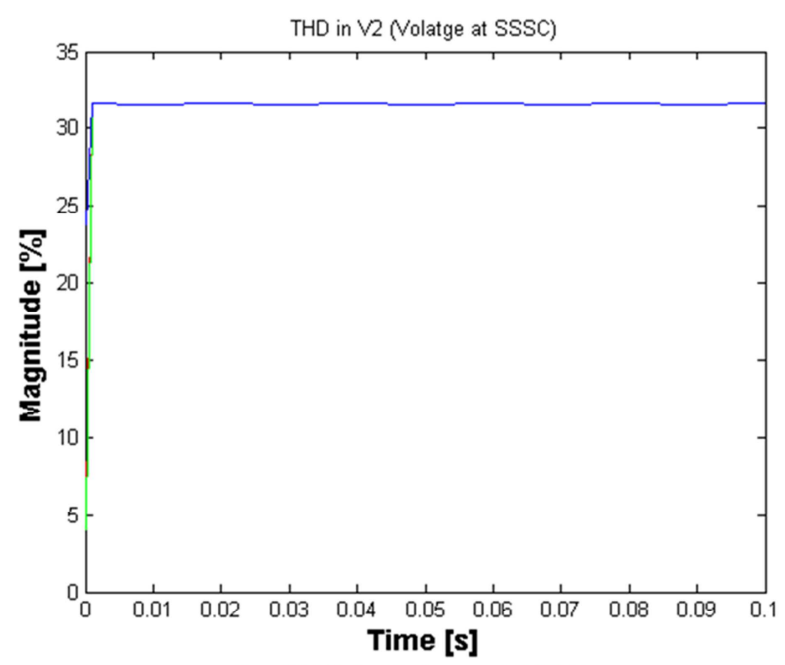

6.a. THD in Voltage at SSSC

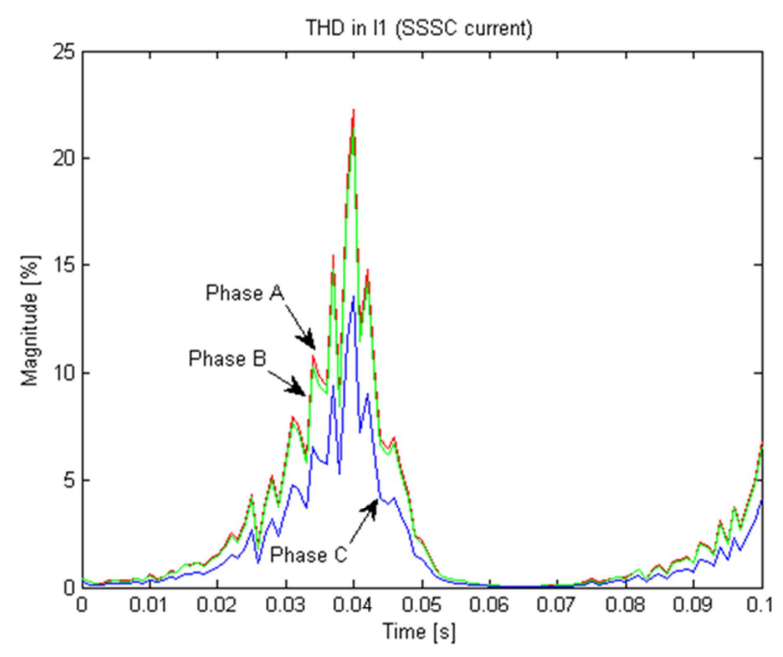

6.b. THD in Current at SSSC

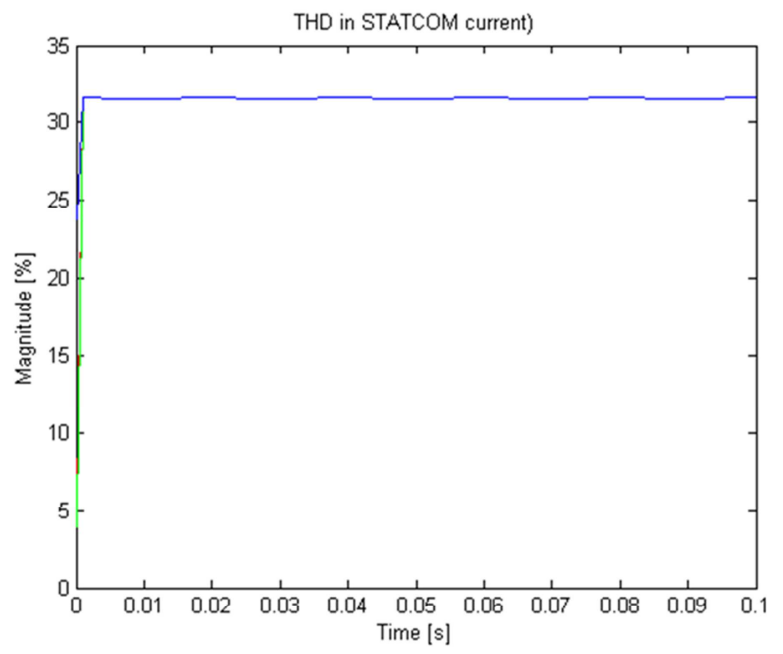

6.c. THD in STATCOM current

Fig. 6. Total harmonic distortion in voltage and current.

\section{References}

[1] C. D. Collins, G. N. Bathurst, N. R. Watson and A. R. Wood," Harmonic domain Approach of STATCOM modelling", IEE proceeding Generation Transmission, Distribution, Vol 152 no.2, pp. 194-200 March 2005.

[2] Juan Segundo - Rmirez and Aurelio Medina," Modelling of FACTS deives based on SPWM VSC", IEEE Transaction on power Delivery Vol.24 No.4, October 2001.

[3] Farhad Yahyaie, and Peter W. Lehn, “On Dynamic Evaluation of Harmonics Using Generalized Averaging Techniques IEEE Transactions On Power Systems", Vol. 30, No. 5, September 2015.

[4] K. L. Lian and P. W. Lehn," Steady-State Solution of a Voltage-Source Converter with Full Closed-Loop Control" IEEE Transactions On Power Delivery, Vol. 21, No. 4, Pp. 2071-2080 October 2006.

[5] Abner Ramirez," The Modified Harmonic Domain: Interharmonics," IEEE Transactions On Power Delivery, Vol. 26, No. 1, Pp. 235-241 January 2011.
[6] J. Jesus Rico, Manuel Madrigal and Enrique Acha," Dynamic Harmonic Evolution Using the Extended Harmonic Domain," IEEE Transactions On Power Delivery, Vol. 18, No. 2, Pp 587-594april 2003.

[7] Bharat Vyakaranam, Manuel Madrigal, F. Eugenio Villaseca and Rick Rarick," Dynamic Harmonic Evolution in FACTS via the Extended Harmonic Domain Method," Power and Energy Conference at Illinois (PECI), 2010. Year: 2010 Pages: 29-38.

[8] Pável Zúñiga-Haro," Harmonic Modeling of Multi-pulse SSSC," IEEE Bucharest Power Tech Conference, June 28th July 2nd, Bucharest, Romania.

[9] Abner Ramirez and J. Jesus Rico," Harmonic/State Model Order Reduction of Nonlinear Networks." IEEE Transactions on Power Delivery, Year 2015.

[10] P. Tripura1, Y. S. Kishore Babu 2, Y. R. Tagore,” Space Vector Pulse Width Modulation Schemes for Two-Level Voltage Source Inverter," ACEEE Int. J. on Control System and Instrumentation, Vol. 02, No. 03, October 2011.

[11] Babita Nanda," Total Harmonic Distortion of Dodecagonal Space Vector Modulation." International Journal of Power Electronics and Drive System (IJPEDS) Vol. 4, No. 3, September 2014, pp. 308-313. 
[12] P. C. Stefanov A. M. Stankovic," Dynamic Phasors in Modeling of UPFC Under Unbalanced Conditions." International Conference on Power System Technology, 2000. Proceedings. PowerCon 2000. Pages: 547-552 vol. 1.

[13] M. Saeedifard, A. R. Bakhshai, G. Joos, P. Jain,” Modified Low Switching Frequency Space Vector Modulators for High Power Multi-Module Converters," Applied Power Electronics Conference and Exposition, 2003. APEC '03. Eighteenth Annual IEEE Pages: 555-561.

[14] M Madrigal and E Acha," Harmonic Modelling Of Voltage Source Converters For Hvdc Stations," Seventh International Conference on AC-DC Power Transmission, 2001 Pp: 125131.

[15] Yao Shu-jun, Song Xiao-yan, Wang Yan, Yan Yu-xin, Yan Zhi,” Research on dynamic characteristics of Unified Power Flow
Controller (UPFC)," 4th International Conference on Electric Utility Deregulation and Restructuring and Power Technologies (DRPT), 2011pp: 490-493.

[16] Ali Ajami, S. H. Hosseini and G. B. Gharehpetian," Modelling and Controlling of UPFC for Power System Transient Studies," Transactions On Electrical Eng., Electronics, And Communications Vol.5, No.2, pp: 29-35 August 2007.

[17] A. Nabavi-Niaki M. R. Iravani," Steady-State And Dynamic Models Of Unified Power Flow Controller (Upfc) For Power System Studies," IEEE Transactions on Power Systems, Vol. 11, No. 4, pp: 1937-1943 November 1996.

[18] Maryam Saeedifard, Hassan Nikkhajoei, Reza Iravani, and Alireza Bakhshai," A Space Vector Modulation Approach for a Multimodule HVDC Converter System," IEEE Transactions On Power Delivery, Vol. 22, NO. 3, pp 1643-1654. JULY 2007. 